\title{
Urgences
}

\section{Madeleine Gagnon, Pensées du poème, Montréal, VLB éditeur,} 1983.

\section{Paul Chanel Malenfant}

Numéro 10, 2e trimestre 1984

\section{Spécial fantasmes}

URI : https://id.erudit.org/iderudit/025163ar

DOI : https://doi.org/10.7202/025163ar

Aller au sommaire du numéro

\section{Éditeur(s)}

Urgences

\section{ISSN}

0226-9554 (imprimé)

1927-3924 (numérique)

Découvrir la revue

Citer ce compte rendu

Malenfant, P. C. (1984). Compte rendu de [Madeleine Gagnon, Pensées $d u$ poème, Montréal, VLB éditeur, 1983.] Urgences, (10), 117-120.

https://doi.org/10.7202/025163ar d'utilisation que vous pouvez consulter en ligne.

https://apropos.erudit.org/fr/usagers/politique-dutilisation/ 


\section{PARUTIONS COMMENTÉES}

PENSÉES DU POĖME, de Madeleine Gagnon, VLB éditeur, 1983. Illustrations: encres de Madeleine Gagnon.

D'entrée de jeu, les titre et sous-titre du dernier livre de Madeleine Gagnon, Pensées du poème. Poésie, signalent l'interférence spéculaire du "réflexif" (de la réflexion et du reflet) au "poétique". Puisque "chaque idée/possède/son être-dechose" (p. 21), l'écriture se dicte dans une intensité immédiate, concise, et sous une rêverie matérielle passionnément attentive à l'intimité et à l'opacité des substances se trame une pensée, elle-même matérialiste, qui s'incarne dans la "traversée du corps", en ce lieu de l'inscription biologique, physiologique de la lettre:

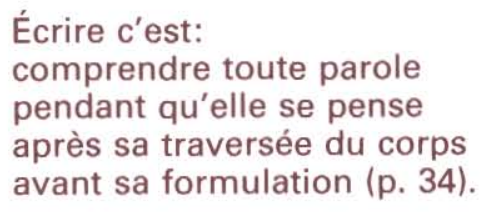

Écrire c'est:

comprendre toute parole pendant qu'elle se pense après sa traversée du corps avant sa formulation (p. 34).

Pensées du poème

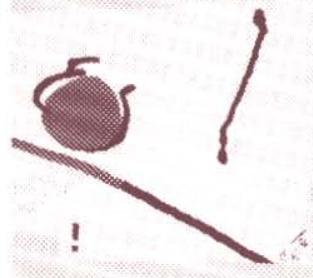

Ainsi, les poèmes sont brefs, resserrés, et ils se donnent sur la page comme des stèles ou de petites pierres debout, gravées d'aphorismes justement péremptoires, de proverbes 
ciselés: "Ce qui te précède/t'appartient/ce que tu laisses/en partage/te quitte" (p. 19). On pourrait croire, à ces quelques exemples, que ce livre prolonge encore la thématisation physique de l'écriture et qu'il s'intéresse à sa genèse dans la procédure même de son énonciation. L'entreprise, ici, porte une autre envergure. Par-delà l'économie des matériaux qui stimulent l'écriture, dans cette concision-condensation textuelle dont l'impact pourrait s'apparenter aux discrets éclats langagiers d'un Gilles Cyr (voir Ce lieu et Diminution d'une pièce, Montréal, Espacement, 1981 et 1983), s'effectue toute une opération de décalque et de subversion délibérée: mimétisme entre l'imaginaire et l'intellect, osmose entre la conscience et l'affect, tous espaces convergents de correspondances et d'échos. Si "le monde est un immense Narcisse en train de se penser", le poète tient le réel à la fois comme prétexte et intertexte pour la "venue à l'écriture", jusqu'à ce que le poème se signifie à lui-même comme son propre palimpseste: "Pas moyen d'écrire autrement/la formule du poème/pour la pensée/(...)/un palimpseste/de surcroît" (p. 30). Certes, cette conscience inscrite du miroir, ces recours à "I'idée" de fiction, ces signaux de la "lecture" et de "I'analyse" perçus comme dicibles dans le poétique pourraient conférer au livre la portée de l'essai, d'autant plus que le genre même ne se dissocie pas de la pratique habituelle de l'auteure. (Après Autographie 1, sont d'ailleurs annoncés "à paraître": Autographie 2, essais et la lettre infinie, essai-poème). Pourtant, en ces "pensées du poème", la poésie, justement, advient. Avec la formule algébrique ou mathématique du texte (les mathématiques, cette "poésie de l'esprit ${ }^{2 "}$ ), avec I'alchimie (cette

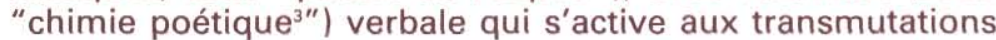
élémentaires, s'inscrit une constante tension oxymorique; tour à tour les dynamismes se crispent ou se dilatent: ainsi, au "mouvement immobile" ("tes pas/qui/maintenant/avancent nulle part" (p. 91)) fera pendant la "mobilité statique" ("I'effervescence/de ceux-là/qui veillent" (p. 10)). En outre, le texte, constamment, porte son propre écho, se rappelle à lui-même son souffle surpris: "Paradoxal/violon/dont l'ouïe est sa voix/ et visibles/les cordes" (p. 12). Cette modulation sonore du sens se répercute dans l'exploration quasi systématique surtout dans la première moitié du livre - du sémantisme 
tonal de l'audition et de l'émission; on entendra les "bruits", la "voix", le "rythme", l'"oreille", le "tympan", I'"ouïe", l'“écho", l' "inouï", tous sèmes qui rappeleront comment "entendre est plus dramatique que voir ${ }^{4 \prime}$. Ainsi, tout se passe comme si le poète convoquait avec une lointaine archéologie de la voix (du logos et de la pensée, de l'“idée dite") les strates primitives du sens: "leur rythme qui se donne/le poème se signe/recueilli/ce testament sonore/des anciens" (p. 18). Cette quête engage une laborieuse remontée de la mémoire, l'interrogatoire analytique (et psychanalytique) de son histoire intime, originelle: "Aussi/dans ton père/te souviens-tu/avoir été/ pensée?" (p. 20). Et du roman familial, ce qui perdure: le cycle: "C'est parce que tu es sortie/de ta mère/que tu peux expulser/ tes enfants" (p. 32).

Depuis la perte (de mémoire?) du père jusqu'au travail de parturiante de la mère, l'écriture elle-même se désire comme rappel et lieu dit d'une pensée (perdue-éperdue) gravée, comme l'effort expulsif d'une inscription substantielle. Ainsi, au fur et à mesure que s'atténue ou se tamise la profération de la voix (se perd, toute voix de naissance...), ce texte déjà lapidaire par le ton ("qui présente la concision, la fermeté du style des inscriptions*. Littré) se constitue comm objet forme et sens - en une véritable "lapidaire", soit en un "Traité sur les pierres précieuses" (Littré). Que l'on ne s'y méprenne pas; rien ici de l'exercice clinquant de la joaillerie sonore ou d'un maniérisme du sens précieux. Dure, la pierre dure et c'est cette consistance durable que convoite le poème. Écrite, cette pierre-poème "pense" (p. 49) et "pleure" (p. 50) et "parle" (p. 51); sa pulsion "donne l'ardoise/l'argilité roche-mère*/et l'ardoise/sur laquelle/s'écrivit/la première dictée" (p. 48). Étonnante métamorphose de l'imaginaire apte à réaliser à partir du corps maternel, lui-même "parcheminé" (p. 16), "tatoué" (p. 22), le corps de l'écriture ("Avant l'être de ce texte/l'écriture sur la paroi/des chairs" (p. 47)) comme pierre angulaire d'une maternité dite, d'une existence scripturaire. Certes, le temps, ce grand sculpteur...

À la mutité pierreuse, on oppose donc l'euphorie de la nomination: "Je nommerai aussi/I'améthyste/ (...) /je nomme-

* C'est nous qui soulignons 
rai ma pierre/mes pierres/celles qui pensent/ et qui me font songer" (p. 59). Et encore: "celles qui me ramènent/à mon corps-monument" (p. 61). Après les voix donc, les pierres de naissance. Un certain lyrisme, celui du chatoiement mesuré, incisif, investit alors les poèmes comme pour attester d'évidence que "I'image de la pierrerie ne se dit pas, elle s'écrit ${ }^{5}$ ". Pour réfuter les mots d'ordre et les tables de loi (l'autorité légiférante), l'écriture-lecture inscrit toutes graphies, elle traduit les hiéroglyphes et les graffiti, bref elle participe à cette libre et inépuisable généalogie des signes. Nul idéalisme subjectif, nulle velléité utopique de réaliser le "nom propre" ne viennent réduire la portée de cette conscience réaliste d'une possible pérennité de I'histoire d'écrire. Car, sur la pierre, l'écriture est anonyme: "comme s'écrit/un chef-d'oeuvre/inconnu" (p. 63).

Pensées du poème: une poésie grave où se profile sous la concision stylistique une fascinante prolifération thématique. Le constat quotidien y côtoie la scène onirique ou fabulée, le miroitement (de la réversibilité de l'idée au poème) s'accorde à l'incision et à la gravure sémantique, le luxe naturel des matières admet la brèche syntaxique ou la saccade du tempo. En peu de mots, ce livre dit (est) un verdict: "je serai rassasiée/ quand je ne serai plus" (p. 13). Ainsi, d'un seul trait décoché sur le vif du sujet s'affirme le désir insatiable, comme s'avoue de ce ton désabusé, sans les contorsions du désespoir, l'allure laconique du néant:

ces mots seuls

me donnent vie

dans la nuit des temps (p. 44).

Certes, avec les mots, je suis dans le réel; et qui donc lira ces vocables sertis sur une pierre de papier, ailleurs, nulle part, là où le temps s'amenuise: "dans la roue qui tourne/l'éternité" (p. 42). (?).

Paul Chanel Malenfant UQAR

1. Gaston Bachelard qui cite Joachim Gasquet. Les autres phrases ou expressions qui portent un appel de note (2 à 5) sont aussi de Bachelard. 